\title{
SYARAT PERLU DAN CUKUP PERCEPATAN MORTALITAS PADA KELOMPOK SURVIVORSHIP YANG MEMENUHI HUKUM GOMPERTZ MENJADI SUATU SINGLE LIFE STATUS
}

\author{
MAZAYA SHARHANA MARSYA \\ Program Studi Matematika, \\ Fakultas Matematika dan Ilmu Pengetahuan Alam, Universitas Andalas, \\ Kampus UNAND Limau Manis Padang, Indonesia, \\ mazayasharhana@gmail.com
}

\begin{abstract}
Abstrak. Status yang dapat bertahan selama semua anggota dari kelompok yang terdiri dari banyak individu masih dapat bertahan hidup dan gagal saat terjadi kematian pertama dari anggota kelompok tersebut disebut joint life status. Paper ini memperlihatkan tentang keadaan dimana suatu joint life status ( $x y$ ) dapat diganti dengan suatu single life status $(w)$ pada kelompok survivorship. Oleh karena itu, asumsi bahwa percepatan mortalitas pada kelompok survivorship memenuhi hukum Gompertz merupakan syarat perlu dan cukup untuk menjamin bahwa setiap pola survival dari joint life status dapat diganti dengan suatu single life status pada kelompok.
\end{abstract}

Kata Kunci: Joint life status, percepatan mortalitas, hukum Gompertz

\section{Pendahuluan}

Status tertanggung merupakan hal yang penting pada pelaksanaan asuransi jiwa, yaitu status yang terdapat definisi dari keberlangsungan hidup dan kegagalan. Menurut jumlah tertanggungnya, status tertanggung pada asuransi jiwa terbagi dua yaitu, single life status dan multiple life status. Salah satu jenis dari multiple life status adalah joint life status.

Pada kelompok survivorship, $X$, peubah acak yang menyatakan usia saat kematian dan $(x)$, seseorang yang berusia $x$ tahun. Untuk individu $(x), T(x)$, peubah acak yang menyatakan waktu sampai kematian $(x)$ dimana $T(x)=X-x$. Untuk joint life status $(x y), T(x y)$, peubah acak yang menyatakan waktu terjadinya kematian pertama dari $(x)$ atau $(y)$ dimana $T(x y)=\min (T(x), T(y))$. Peluang hidup $(x)$ dinotasikan ${ }_{t} p_{x}$ dan peluang mati $(x)$ dinotasikan ${ }_{t} q_{x}$. Notasi ${ }_{t} p_{x}$ menyatakan peluang ( $x$ )akan bertahan hidup sampai usia $x+t$ tahun, sedangkan notasi ${ }_{t} q_{x}$ menyatakan peluang $(x)$ akan meninggal dalam $t$ tahun dan juga merupakan fungsi sebaran dari $T(x)$ atau dapat ditulis

$$
F_{T(x)}(t)={ }_{t} q_{x} .
$$

Pada pelaksanaan asuransi jiwa, jumlah orang yang berusia $x$ tahun selalu berkurang. Tingkat penurunan ini dikenal dengan percepatan mortalitas. Pada 
tahun 1825, Benjamin Gompertz mengemukakan dalil dari bentuk analitik untuk percepatan mortalitas yang dikenal dengan hukum Gompertz [1].

Percepatan mortalitas pada usia $t$ pada kelompok survivorship dinyatakan sebagai

$$
\mu(t)=\frac{f_{X}(t)}{1-F_{X}(t)}, \quad t \geq 0
$$

dimana $f_{X}(t)$ dan $1-F_{X}(t)$ adalah fungsi kepekatan peluang dan fungsi sebaran dari $X$. Percepatan mortalitas dari $(x)$ pada usia $x+t$ yang dinotasikan dengan $\mu_{T(x)}(t)$ sama dengan $\mu(x+t)$. Peluang hidup $(x)$ dapat didefinisikan menggunakan percepatan mortalitas sebagai berikut

$$
{ }_{n} p_{x}=\exp \left(-\int_{0}^{n} \mu(x+s) d s\right) .
$$

Makalah ini memperlihatkan tentang keadaan dimana suatu joint life status dapat diganti dengan suatu single life status pada kelompok survivorship. Oleh karena itu, asumsi bahwa percepatan mortalitas pada kelompok survivorship memenuhi hukum Gompertz merupakan syarat perlu dan cukup untuk menjamin bahwa setiap pola survival dari joint life status dapat diganti dengan suatu single life status pada kelompok survivorship.

\section{Pembentukan Joint Life Status Menjadi Single Life Status}

Untuk menyederhanakan evaluasi dari integral-integral yang melibatkan banyak jiwa, terdapat beberapa asumsi tentang sebaran survival (survival distribution). Pada tahun 1825, Gompertz memperkenalkan asumsi penting sebagai berikut.

Asumsi 2.1. [3] Percepatan mortalitas pada kelompok survivorship memenuhi hukum Gompertz, yaitu $\mu(x)=B c^{x}$ dimana $B$ dan $c$ adalah konstanta, $B>0$ dan $c>1$.

Karena percepatan mortalitas dari joint life status adalah penjumlahan percepatan mortalitas dari banyak jiwa yang terkait, maka pada kasus ini, dapat diganti suatu joint life status (xy) menjadi single life status (w) yang memenuhi $\mu_{T(x y)}(t)=\mu(w+t)$ dengan $t \geq 0$,

$$
\mu(x+t)+\mu(y+t)=\mu(w+t), \quad t \geq 0 .
$$

Karena keberadaan single life status pada kasus biasa belum diketahui secara pasti, maka diberikan asumsi berikut.

Asumsi 2.2. [3] Pada suatu kelompok survivorship, untuk setiap dua jiwa (x) dan (y), terdapat suatu single life status (w) pada kelompok tersebut, sedemikan sehingga fungsi sebaran dari $T(w)$ dan $T(x y)$ sama.

Untuk selanjutnya, percepatan mortalitas $\mu(t)$ diasumsikan kontinu pada $[0,+\infty)$. Berikut beberapa lema dan teorema pendukung untuk penyelesaian masalah utama. 
Lema 2.3. [3] Fungsi $\mu(x)=B c^{x}$ memenuhi

$$
\int_{0}^{\infty} \mu(x) d x=\infty
$$

yang mana adalah syarat perlu dan cukup untuk $\mu$ menjadi percepatan mortalitas.

Bukti. $(\Rightarrow)$ Untuk $\mu(x)=B c^{x}$, maka dapat dengan mudah ditunjukkan $\int_{0}^{\infty} \mu(x) d x=\infty$.

$(\Leftarrow)$ Karena percepatan mortalitas $\mu(x)$ adalah suatu ukuran kerentanan seseorang terhadap kematian, maka menurut Gompertz seperti yang disebutkan pada [4], $\frac{1}{\mu(x)}$ adalah suatu ukuran ketahanan seseorang terhadap kematian. Jadi untuk $k=\log c$ dimana $c$ adalah konstanta, maka dapat ditulis sebagai [4]

$$
\frac{d}{d x}\left(\frac{1}{\mu(x)}\right)=-k \frac{1}{\mu(x)} \text {. }
$$

Dari persamaan (2.3) diperoleh bentuk [2],

$$
\log \left(\frac{1}{\mu(x)}\right)=-k x-\log B
$$

dimana $-\log B$ adalah bilangan konstan dari integral parsial. Dengan mengeksponensialkan ruas kiri dan kanan pada persamaan (2.4), maka didapatkan $\mu(x)=B c^{x}$ dimana fungsi $\mu(x)$ tersebut menyatakan percepatan mortalitas.

Lema 2.4. [3] Misalkan $g \in C[0,+\infty)$ memenuhi

$$
g(x+y)=g(x) \cdot g(y)
$$

untuk setiap $x, y>0$, dan $g(x) \not \equiv 0$. Maka untuk setiap $x \geq 0$,

$$
g(x)=c^{x} \text { dengan } \quad c=g(1) .
$$

Bukti. Pembuktian dilakukan dengan cara kontradiksi. Diasumsikan bahwa $g$ adalah suatu fungsi dengan domain $[0,+\infty)$. Misalkan untuk suatu $t \geq 0, g(t) \neq c^{t}$ dengan $c=g(1)$. Misalkan $g(t)>c^{t}$, ini berarti $g$ adalah fungsi naik. Misalkan $t=0$ adalah suatu titik ujung interval, oleh karena itu fungsi $g(t)>c^{t}$ tidak bisa dikatakan kontinu di $t=0$. Hal ini kontradiksi, karena $g \in C[0,+\infty)$ yaitu $g$ merupakan fungsi kontinu pada $[0,+\infty)$. Misalkan $g(t)<c^{t}$, ini berarti $g$ adalah fungsi turun. Dengan alasan yang sama dapat disimpulkan bahwa fungsi $g(t)<c^{t}$ tidak bisa dikatakan kontinu di $t=0$. Hal ini kontradiksi, karena $g \in C[0,+\infty)$ yaitu $g$ merupakan fungsi kontinu pada $[0,+\infty)$. Karena pemisalan untuk suatu $t \geq 0, g(t) \neq c^{t}$ dengan $c=g(1)$ menunjukkan kontradiksi, maka haruslah $g(t)=c^{t}$ dengan $c=g(1)$. Dengan begitu Lema 2.4 berlaku.

Lema 2.5. [3] Misalkan $\mu(x)$ adalah fungsi yang terdefinisi. Maka $\mu(x)$ tak terbatas $\operatorname{pada}[0,+\infty)$.

Bukti. Misalkan

$$
\mu \not \equiv 0,
$$


terdapat suatu titik $z_{0} \geq 0$ sedemikian sehingga $\mu\left(z_{0}\right)>0$. Misalkan $w$ yang terdefinisi pada (2.1) adalah suatu fungsi yaitu $w:[0,+\infty) \times[0,+\infty) \rightarrow[0,+\infty)$ sedemikian sehingga untuk setiap $x, y, t \geq 0$,

$$
\mu(x+t)+\mu(y+t)=\mu(w(x, y)+t) .
$$

Dengan memilih $x=y=0$ pada (2.8) maka,

$$
2 \mu(t)=\mu(w(0,0)+t) .
$$

Jika $w(0,0)=0$, maka $\mu(t) \equiv 0$. Hal ini kontradiksi dengan (2.8). Oleh karena itu, haruslah $w(0,0)>0$. Dapat ditulis kembali (2.9) menjadi

$$
2^{m} \mu\left(z_{0}\right)=\mu\left(m w(0,0)+z_{0}\right)
$$

dimana $m>0$. Notasikan $z_{m}=m w(0,0)+z_{0}$. Dengan memisalkan $m \rightarrow \infty$ pada (2.10), maka $\mu\left(z_{m}\right) \rightarrow+\infty$. Oleh karena $\mu\left(z_{m}\right)$ tak terbatas, maka fungsi $\mu(x)$ tak terbatas pada $[0,+\infty)$.

Lema 2.6. [3] Misalkan $\mu(x)$ dan $w(x, y)$ adalah dua fungsi yang terdefinisi, dan $\mu(x)$ memenuhi $\mu \in C^{1}(0,+\infty)$. Maka terdapat dua konstanta yaitu $B>0, c>1$ sedemikian sehingga untuk setiap $x, y \geq 0$

$$
\mu(x)=B c^{x}, w(x, y)=\frac{\ln \left(c^{x}+c^{y}\right)}{\ln c} .
$$

Bukti. Misalkan $y=0$ pada (2.8) dan notasikan $f(x)=w(x, 0)$. Maka (2.8) menjadi

$$
\mu(x+y)+\mu(y)=\mu(f(x)+y)
$$

untuk setiap $x, y>0$, dimana $f \in C^{1}[0,+\infty)$. Turunkan persamaan (2.12) terhadap $x$ dan $y$ maka didapatkan secara berturut-turut untuk setiap $x, y>0$ yaitu

$$
\begin{aligned}
& \mu^{\prime}(x+y)=\mu^{\prime}(f(x)+y) f(x) \text { dan } \\
& \mu^{\prime}(x+y)+\mu^{\prime}(y)=\mu^{\prime}(f(x)+y) .
\end{aligned}
$$

Subtitusikan (2.14) ke (2.13) sehingga untuk setiap $x, y>0,(2.13)$ menjadi

$$
\mu^{\prime}(y) f^{\prime}(x)=\mu^{\prime}(x+y)\left(1-f^{\prime}(x)\right) .
$$

Pertukarkan $x$ dan $y$ pada (2.15) maka

$$
\mu^{\prime}(x) f^{\prime}(y)=\mu^{\prime}(x+y)\left(1-f^{\prime}(y)\right) .
$$

Kemudian untuk setiap $x>0$, nyatakan

$$
f^{\prime}(x) \neq 1, f^{\prime}(x) \neq 0 \text {. }
$$

Sebaliknya, terdapat suatu titik $x_{0}>0$ sedemikian sehingga $f^{\prime}\left(x_{0}\right)=1$ atau $f^{\prime}\left(x_{0}\right)=0$. Jika dimisalkan $x=x_{0}$ pada (2.15), maka akan mengakibatkan kontradiksi dengan Lemma 2.3. Oleh karena itu, (2.17) berlaku.

Kemudian notasikan $g(x)=\frac{f^{\prime}(x)}{1-f^{\prime}(x)}$. Dari (2.15) dan (2.16) didapatkan

$$
\mu^{\prime}(x+y)=g(y) \mu^{\prime}(x)=g(x) \mu^{\prime}(y),
$$


yang berarti bahwa untuk setiap $x, y>0$,

$$
\frac{\mu^{\prime}(x)}{g(x)}=\frac{\mu^{\prime}(y)}{g(y)}=C
$$

dengan $C \neq 0$ adalah suatu konstanta. Berdasarkan (2.18), didapatkan $g(x+y)=$ $g(x) g(y)$. Karena $g(x) \neq 0$, dengan menggunakan Lemma 2.2 dapat disimpulkan bahwa $g(x)=c^{x}$ dengan $c=g(1)>0$. Dengan menggunakan penyelesaian persamaan diferensial biasa pada (2.19), untuk setiap $x>0$,

$$
\mu(x)=A+B c^{x},
$$

dimana $A, B$ adalah konstanta. Dengan memilih $x=y=0$ pada (2.8) maka untuk setiap $t \geq 0$,

$$
2(\mu(t))=2\left(A+B c^{t}\right)=\mu(w(0,0)+t)=A+B c^{w(0,0)+t},
$$

yang berarti $A=0$ dan $c=2^{\frac{1}{w(0,0)}}$. Karena $\mu(x) \geq 0$ terbatas, maka $B>0$ dan $c>1$. Dengan penghitungan langsung, diperoleh bahwa $w(x, y)=\frac{\ln \left(c^{x}+c^{y}\right)}{\ln c}$.

Teorema 2.7. [3] Misalkan $\mu:[0,+\infty) \rightarrow[0,+\infty)$ adalah suatu fungsi kontinu dan tak negatif yang memenuhi $\mu \neq \equiv$. Jika terdapat suatu fungsi $w:[0,+\infty) \times$ $[0,+\infty) \rightarrow[0,+\infty)$ sedemikian sehingga untuk setiap $x, y, t \geq 0$,

$$
\mu(x+t)+\mu(y+t)=\mu(w(x, y)+t) .
$$

Maka untuk setiap $x, y \geq 0$,

$$
\mu(x)=B c^{x}, \quad w(x, y)=\frac{\ln \left(c^{x}+c^{y}\right)}{\ln c},
$$

dimana $B$ dan $c$ adalah konstanta, yaitu $B>0$ dan $c>1$.

Bukti. Misalkan $\phi(x) \in C_{0}^{\infty}$ adalah fungsi yang memenuhi $\phi \geq 0$, sup $\phi \subset(-1,1)$ dan $\int_{-} 1^{1} \phi(x) d x=1$. Untuk setiap $\varepsilon, \quad 0 \leq \varepsilon \leq 1$, misalkan

$$
\phi_{\varepsilon}(x)=\frac{1}{\varepsilon} \phi\left(\frac{x}{\varepsilon}\right)
$$

dan definisikan

$$
\mu_{\varepsilon}(x)=\int_{-\varepsilon}^{\varepsilon} u(x-z) \phi_{\varepsilon}(z) d z=\int_{x-\varepsilon}^{x+\varepsilon} \mu(z) \phi_{\varepsilon}(x-z) d z
$$

Untuk setiap $x \geq \varepsilon$. Jelas bahwa $\mu_{\varepsilon} \in C^{\infty}[\varepsilon,+\infty)$. Dari (2.8) untuk setiap $t \geq \phi$ dan $x, y \geq 0$, maka

$$
v_{\varepsilon}(x+t)+v_{\varepsilon}(y+t)=v_{\varepsilon}(w(x, y)+t) .
$$

Berdasarkan Lema 2.4 terdapat $\bar{B}_{\varepsilon}>0$ dan $c_{\varepsilon}>1$ sedemikian sehingga $v_{\varepsilon}(x)=$ $\bar{B}_{\varepsilon} c_{\varepsilon}^{x}$. Jadi, untuk setiap $x \geq \varepsilon$,

$$
\mu_{\varepsilon}(x)=v_{\varepsilon}(x-\varepsilon)=\bar{B}_{\varepsilon} c_{\varepsilon}^{x-\varepsilon}=B_{\varepsilon} c_{\varepsilon}^{x}
$$

dimana $B_{\varepsilon}=\bar{B}_{\varepsilon} c_{\varepsilon}^{-\varepsilon}$. Tetapkan titik sebarang $x \in(0,+\infty)$ dan untuk setiap $x \leq \varepsilon$, berlaku $\mu_{\varepsilon}(x)$. Karena $\mu(x)$ kontinu, maka untuk setiap $x>0$

$$
\mu_{\varepsilon}(x) \rightarrow \mu(x) \text { dengan } \varepsilon \rightarrow 0 .
$$


Dengan kata lain, untuk setiap $x \in(0,+\infty)$,

$$
B_{\varepsilon} c_{\varepsilon}^{x} \rightarrow \mu(x) \text { dengan } \varepsilon \rightarrow 0 .
$$

Misalkan $z_{0} \geq 0$ sedemikian sehingga $\mu\left(z_{0}\right)>0$. Dari (2.9) dan(2.10) diperoleh

$$
2 \mu\left(z_{0}\right)=\mu\left(w(0,0)+z_{0}\right), \quad 4 \mu\left(z_{0}\right)=\mu\left(2 w(0,0)+z_{0}\right)
$$

Dari (2.25) diperoleh,

$$
c_{\varepsilon}^{w(0,0)}=\frac{\mu_{\varepsilon}\left(2 w(0,0)+z_{0}\right)}{\mu_{\varepsilon}\left(w(0,0)+z_{0}\right)} \rightarrow \frac{\mu\left(2 w(0,0)+z_{0}\right)}{\mu\left(w(0,0)+z_{0}\right)}=2,
$$

yang berarti bahwa $c_{\varepsilon} \rightarrow c=2^{\frac{1}{w(0,0)}}$. Selanjutnya didapatkan

$$
B_{\varepsilon}=\frac{\mu_{\varepsilon}\left(z_{0}\right)}{c_{\varepsilon}^{z_{0}}} \rightarrow \frac{\mu\left(z_{0}\right)}{c^{z_{0}}}=B>0 .
$$

Oleh karena itu, $\mu(x)=B c^{x}$ untuk setiap $x>0$. Karena $\mu(x)$ kontinu pada $x=0$, maka persamaan pertama pada (2.11) berlaku untuk setiap $x \geq 0$. Dan dengan penghitungan langsung persamaan kedua pada pada (2.11) juga berlkau. Karena $\mu(x) \geq 0$ tak terbatas, maka $c>1$.

Dari beberapa Lemma dan Teorema pendukung yang sudah di buktikan, maka diberikan Teorema utama sebagai berikut.

Teorema 2.8. Asumsi 1 benar jika dan hanya jika Asumsi 2 benar.

Bukti. $(\Rightarrow)$ Misalkan percepatan mortalitas pada kelompok survivorship untuk setiap jiwa memenuhi hukum Gompertz. Berdasarkan (2.1), suatu joint life status $(x y)$ dapat diganti dengan suatu single life status $(w)$. Berdasarkan (1.1) dan (1.2) maka

$$
F_{T(x y)}(t)=1-{ }_{t} p_{x} y=1-\exp \left(-\int_{0}^{t} \mu_{T(x y)}(s) d s\right) .
$$

Sehingga (2.26) dapat ditulis kembali menjadi

$$
\begin{aligned}
F_{T(x y)} & =1-\exp \left(-\int_{0}^{t} \mu(x+s)+\mu(y+s) d s\right) \\
& =1-\exp \left(-\int_{0}^{t} \mu(w+s) d s\right) \\
& =F_{T(w)}(t) .
\end{aligned}
$$

Dari (2.27) diperoleh bahwa $F_{T(x y)}(t)=F_{T(w)}(t)$. Jadi, dapat disimpulkan bahwa Asumsi 1 benar jika Asumsi 2 benar.

$(\Leftarrow)$ Berdasarkan Teorema 2.5 maka dapat disimpulkan bahwa Asumsi 2 benar jika Asumsi 1 benar. 


\section{Contoh Kasus}

\section{Kasus 1.}

Misalkan terdapat dua orang yaitu $(x)$ dan $(y)$ dalam kelompok survivorship yang hendak mengikuti asuransi jiwa bersama joint life. Diasumsikan bahwa percepatan mortalitas dari kedua orang tersebut memenuhi hukum Gompertz. Diberikan terlebih dahulu ketentuan-ketentuan sebagai berikut:

- Usia $x$ adalah 40 tahun,

- Usia y adalah 50 tahun,

- $B=0.0001$ dan $c=10^{0.04}$,

- Pada $t=20$ tahun kemudian, $(x)$ dan $(y)$ masih dapat bertahan hidup.

Berdasarkan ilustrasi di atas, maka dengan menggunakan (2.1) diperoleh persamaan $c^{x}+c^{y}=c^{w}$, sehingga diperoleh $w=53.63851$. Selanjutnya, berdasarkan (1.1) dan (1.2) dimana percepatan mortalitasnya memenuhi hukum Gompertz maka untuk $w=53.63851, B=0.0001, c=10^{0.04}$ dan $t=20$ diperoleh

$$
F_{T(53.63851)}(20)=0.55335008 \approx 0.5533501 .
$$

Dan untuk $(x)=40,(y)=50, B=0.0001, c=10^{0.04}$ dan $t=20$

$$
F_{T(40)(50)}(20)=0.55335008 \approx 0.5533501 .
$$

Karena (3.1) dan (3.2) hasilnya sama, maka asumsi bahwa percepatan mortalitas memenuhi hukum Gompertz adalah syarat perlu dan cukup untuk menjamin bahwa setiap pola survival dari joint life status ( $x y$ ) dapat diganti dengan suatu single life status $(w)$ pada kelompok.

\section{Kasus 2.}

Misalkan terdapat dua orang yaitu $(x)$ dan $(y)$ dalam kelompok survivorship yang hendak mengikuti asuransi jiwa bersama joint life. Diasumsikan bahwa untuk setiap dua jiwa $(x)$ dan $(y)$, terdapat single life status $(w)$ sedemikian sehingga fungsi sebaran dari peubah acak sisa usia $(w)$ yang dinotasikan dengan $T(w)$ dan fungsi sebaran dari perubah acak sisa usia ( $x y)$ yang dinotasikan dengan $T(x y)$ sama. Diberikan terlebih dahulu ketentuan-ketentuan sebagai berikut:

- Usia $x$ adalah 40 tahun,

- Usia y adalah 50 tahun,

- Usia $w$ adalah 53.63851 tahun,

- Pada $t=20$ tahun kemudian, $(x),(y)$ dan $(w)$ masih dapat bertahan hidup.

Berdasarkan asumsi dari ilustrasi diatas maka diketahui, $F_{T(x)(y)}(t)=F_{T(w)}(t)$. Berdasarkan (1.1) dan (1.2) maka secara berturut-turut

$$
\begin{gathered}
F_{T(w)}(t)=1-\exp \left(-\int_{0}^{t} \mu(w+s) d s\right) d a n \\
F_{T(x y)}(t)=1-\exp \left(\left(-\int_{0}^{t} \mu(x+s) d s\right)+\left(-\int_{0}^{t} \mu(y+s) d s\right)\right)
\end{gathered}
$$


Terlebih dahulu akan disederhanakan (3.3). Berdasarkan (2.4), maka

$$
\log \left(\frac{1}{\mu(w+s)}\right)=-k(w+s)-\log B .
$$

Kemudian eksponensialkan (3.5), sehingga (3.5) menjadi

$$
\mu(w+s)=B c^{(w+s)} .
$$

Kemudian subtitusikan (3.6) ke (3.3), sehingga (3.3) dapat ditulis kembali menjadi

$$
F_{T(w)}(t)=1-\exp \left(-\int_{0}^{t} B c^{(w+s)} d s\right) .
$$

Dengan argumen yang sama, maka (3.4) dapat ditulis kembali menjadi

$$
F_{T(x y)}(t)=1-\exp \left(\left(-\int_{0}^{t} B c^{(x+s)} d s\right)+\left(-\int_{0}^{t} B c^{(y+s)} d s\right)\right)
$$

Dengan begitu dapat diperoleh sebagai berikut,

$$
F_{T(x y)}(t)=F_{T(w)}(t),
$$

yaitu,

$1-\exp \left(-\int_{0}^{t} B c^{(w+s)} d s\right)=1-\exp \left(\left(-\int_{0}^{t} B c^{(x+s)} d s\right)+\left(-\int_{0}^{t} B c^{(y+s)} d s\right)\right)$, atau

$$
c^{x}+c^{y}=c^{w} .
$$

Karena $B$ dan $c$ suatu kontanta, untuk $(w)=53.63851,(x)=40,(y)=50$, dan $t=20$, hanya dipenuhi oleh $B=0.0001$ dan $c=10^{0} .04$. Oleh karena percepatan mortalitas dari $(x y)$ dan $(w)$ memenuhi hukum Gompertz, maka asumsi bahwa percepatan mortalitas memenuhi hukum Gompertz adalah syarat perlu dan cukup untuk menjamin bahwa setiap pola survival dari joint life status ( $x y$ ) dapat diganti dengan suatu single life status $(w)$ pada kelompok.

\section{Kesimpulan}

Pada kelompok survivorship, joint life status ( $x y$ ) dapat diganti dengan suatu single life status $(w)$ dengan syarat fungsi sebaran peubah acak waktu sampai kematian dari $(x y)$ dan $(w)$ sama. Untuk itu, Asumsi bahwa percepatan mortalitas pada kelompok survivorship memenuhi hukum Gompertz adalah suatu jaminan bahwa setiap pola survival dari joint life status dapat diganti dengan suatu single life status pada kelompok.

\section{Daftar Pustaka}

[1] Bowers, Newton L., et al. 1997. Actuarial Mathematics. The Society of Actuaries, Illinois

[2] Futami, Takashi. 1993. Matematka Asuransi Jiwa, Bagian I . Terj. Dari Seimei Hoken Sogaku, Jokan (92 Revision), oleh Heriyanto, G. Penerbit Incorporated Foundation Oreinetal Life Insurance Cultural Development Center, Japan 
Percepatan Mortalitas pada Kelompok Survivorship Memenuhi Hukum Gompertz 37

[3] Jingping Yang dan Shulin Zou. 2003. Joint-life status and Gompert's law. Advance in Mathematics, Peking University, Beijing. 32:74-80

[4] Turner, E.L dan J.A. Hanley. 2010. Cultural Imagery and Statistical Models of the Force of Mortality: Addison, Gompertz and Pearson. J. R. Statist. Soc. A. 173: Part 4 